\title{
New insight on the behaviour of the irreversible adsorption and underpotential deposition of thallium on platinum (111) and vicinal surfaces in acid electrolytes.
}

\author{
P.Rodriguez, ${ }^{a}$ N.García-Aráez, ${ }^{b}$ E.Herrero ${ }^{c}$ and J. M. Feliu. ${ }^{c}$ \\ ${ }^{a}$ School of Chemistry, University of Birmingham, B15 2TT Birmingham, UK \\ ${ }^{\mathrm{b}}$ School of Chemistry, University of Southampton, Highfield, SO17 1BJ Southampton, UK \\ ${ }^{c}$ Departamento de Química Física and Instituto de Electroquímica, Universidad de \\ Alicante, Apdo. 99, E-03080 Alicante, Spain
}

\begin{abstract}
We report, for the first time, the electrochemical behaviour of thallium irreversibly adsorbed on $\mathrm{Pt}$ (111) and platinum stepped surfaces composed of (111) terraces and monoatomic steps. Similar to the case of thallium UPD, the voltammograms obtained after thallium irreversible adsorption present three characteristic features. After a careful analysis of the effect of the thallium concentration, the concentration and nature of the anion of the supporting electrolyte and the $\mathrm{pH}$ of the solution on these voltammetric features, we have been able to ascribe these processes to $\mathrm{Tl} / \mathrm{Tl}^{+}$oxidation and anion adsorption on the $\mathrm{Tl}$ modified surface. In addition, the results obtained with stepped surfaces, indicate that some of the features are clearly associated to the presence of (111) surface domains, and thus they could be used for the quantification of these sites.
\end{abstract}




\section{Introduction}

In order to understand the nature of different heterogeneous processes taking place in the metal-electrolyte interface, it is essential to control the structure of the base metal. The use of single crystal electrodes (with well-defined surface structure) has made this study possible. In the field of the electrochemistry, the use of the cyclic voltammetry with well-defined single crystal electrodes can provide information about the effect of the surface structure on electrochemical reactions. In most cases different geometric sites involve different electrochemical responses for specific reactions. Of special interest is the study of the surface composition of electrodes with well-defined structure on electrochemical reactions. There are two methods that allowed the controlled deposition of adatoms on metal electrodes: underpotential deposition (UPD) ${ }^{1}$ and irreversible adsorption, ${ }^{2-5}$ also called spontaneous deposition. ${ }^{6-9}$

UPD is the electrochemical formation of non-bulk surface adlayers at potentials more positive than those of the Nerst potentials corresponding to the bulk deposition of the adsorbate. On the other hand, irreversible adsorption of a foreign adatom occurs when the adatom remains adsorbed on the surface in a wide potential range, despite the fact that the solution does not contain ions of the adatom that could be in equilibrium with the adsorbed species. It could be considered that irreversible adsorption is a particular case of UPD, one in which the adsorbed adatom has a lower oxidation state than the species in solution, within a certain potential window. ${ }^{1,3-5,10}$ As a result, the desorption rate would contain an exponential term of the difference of the equilibrium potential and the working potential. Since this difference is negative (see above definition of UPD) and is usually very large, the desorption rate is reduced to a negligible value. The desorption of the adatom occurs during 
a surface redox reaction involving the oxidation state of the species in solution. In many cases, the adatoms also suffer surface redox reactions on the surface of the metal without desorption of the species.

Most UPD and irreversible adsorption processes are surface sensitive reactions. ${ }^{1}$ Also, the effects of anions on the UPD of metals plays an important role. ${ }^{11-16}$ The applications of surfaces modified by metals are numerous: from the catalysis of the electro-oxidation of organic substances to the simulation of crystal nucleation and growth. ${ }^{17,18}$ The combination of electrochemical and spectroelectrochemical methods has produced interesting studies to of the structure of metallic and anion adsorbates. ${ }^{1,19-21}$ In the case of thallium UPD, we report in this paper that the irreversible adsorption of thallium is strongly influenced by the anion in solution. Co-adsorption of perchlorate and sulphate in the UPD of thallium has been reported previously. ${ }^{21-23}$ Strong changes in the CV of thallium UPD in a solution containing halogen anions indicate co-adsorption with those anions. ${ }^{24}$ As far as we know, the behaviour of thallium irreversibly adsorbed on Pt (111) surfaces has not been reported before. Only a few electrochemical studies have been published on the stability of thallium adsorbed on Pt step surfaces ${ }^{25}$ and on the change in the catalytic effect of polycrystalline platinum surfaces doped with amounts of thallium on the oxidation of formic acid. ${ }^{26}$

The aim of this paper is to study the irreversible adsorption of thallium on $\mathrm{Pt}(111)$ in $0.5 \mathrm{M} \mathrm{H}_{2} \mathrm{SO}_{4}$ and $0.1 \mathrm{M} \mathrm{HClO}_{4}$ by means of voltammetric measurements, and to compare it with thallium UPD. The discussion will be based on the surface redox processes undergone by the adatom and the modification of hydrogen and the anion upon the thallium adsorption. 


\section{Experimental}

Platinum single crystal electrodes were oriented, cut and polished from small single crystal platinum beads $(2.5 \mathrm{~mm}$ diameter) following the procedure described by Clavilier and co-workers. ${ }^{27}$ The electrodes were cleaned by flame annealing, cooled down in $\mathrm{H}_{2} / \mathrm{Ar}$ (N50, Air Liquid in all gases used) and protected with water in equilibrium with this gas mixture to prevent contamination before immersion in the electrochemical cell, as described elsewhere.

Irreversible adsorption of thallium was performed introducing the electrode into a solution of $\mathrm{Tl}_{2} \mathrm{CO}_{3}$ with concentrations between $10^{-6}$ and $10^{-2} \mathrm{M}$ in the presence of a supporting electrolyte (either $0.5 \mathrm{M} \mathrm{H}_{2} \mathrm{SO}_{4}$ or $0.1 \mathrm{M} \mathrm{HClO}_{4}$ ). The electrode with a droplet of solution attached was immersed in the cell at $0.1 \mathrm{~V}$. Contamination of the cell by residual thallium ions is negligible for all the experiments shown here. Small amounts of thallium ions in solution are easily detected because they will lead to the blockage of the surface sites of a flame-annealed $\operatorname{Pt}(111)$ electrode that is initially free of thallium on the surface. The underpotential deposition experiments were performed as described previously. $^{22,23}$

Experiments were carried out at room temperature, $25^{\circ} \mathrm{C}$, using two classical twocompartment electrochemical cells de-aerated with Ar and including a platinum counter electrode and a reversible hydrogen electrode (RHE) as references. All potentials in this paper are referred to the RHE scale, except where otherwise stated. Solutions were prepared from $\mathrm{H}_{2} \mathrm{SO}_{4}$ and $\mathrm{HClO}_{4}$ (doubly distilled, Aldrich), $\mathrm{K}_{2} \mathrm{SO}_{4}(99.998 \%$, SigmaAldrich) and recrystallized $\mathrm{KClO}_{4}\left(>99.999 \%\right.$, Aldrich), $\mathrm{Tl}_{2} \mathrm{CO}_{3}(99.99 \%$, Sigma) and ultrapure water from Elga $\left(18.2 \mathrm{M} \Omega \mathrm{cm}^{-1}\right)$. 


\section{Results and discussion}

\subsection{Electrochemical behavior of UPD and irreversibly-adsorbed thallium on $\operatorname{Pt}(111)$}

in sulfuric solutions

Figure 1 shows the voltammetric behaviour of the thallium UPD on $\operatorname{Pt}(111)$ surfaces in $0.5 \mathrm{M} \mathrm{H}_{2} \mathrm{SO}_{4}+10^{-2} \mathrm{M} \mathrm{Tl}$ and $0.1 \mathrm{M} \mathrm{HClO}_{4}+10^{-2} \mathrm{M} \mathrm{Tl}$. The profiles in absence of thallium are included for comparison. In the UPD profile of $\mathrm{Tl}$, three different regions can be distinguished: i) at high potentials, above $0.7 \mathrm{~V}$, a pair of peaks appears at around $0.75 \mathrm{~V}$ in $0.5 \mathrm{M}$ sulphuric acid and at $0.67 \mathrm{~V}$ in perchloric acid, respectively; these pairs of peaks are associated to the deposition/desorption process of $\mathrm{Tl} / \mathrm{Tl}^{+}{ }^{23}$ in sulphuric acid media, the charge measured under this peak is consistent with a thallium coverage $0.25 ;^{23}$ ii) the peaks appearing in the second region, between 0.3 and $0.6 \mathrm{~V}$, are mainly associated to the adsorption/desorption process of the anions (either sulphate in sulphuric acid solution or $\mathrm{OH}$ or perchlorate in perchloric acid solutions, respectively), ${ }^{22,23}$ in the case of sulphuric acid, SXS measurements have revealed the presence of a $(\sqrt{3} \times \sqrt{3}) \mathrm{R} 30^{\circ}$ sulphate adlayer on the thallium UPD layer at $0.7 \mathrm{~V} \mathrm{RHE} ;{ }^{22}$ the adsorption/desorption of the sulphate adlayer on the thallium-modified surface between 0.6 and $0.3 \mathrm{~V}$ gives a voltammetric profile that is similar to that obtained for the adsorption/desorption the sulphate layer on the unmodified $\operatorname{Pt}(111)$ electrode, at potentials between 0.5 and $0.3 \mathrm{~V}$; iii) in the low potential region (below $0.3 \mathrm{~V}$ ), no significant currents are recorded aside from a small pair of peaks at 0.2 and 0.19 $\mathrm{V}$; this fact implies that the hydrogen adsorption process typical of $\operatorname{Pt}(111)$ electrodes has been suppressed by the adsorption of thallium. 
From the comparison of the thallium UPD in both electrolyte media, it can be seen that peak potentials of all the processes depend on the supporting electrolyte, indicating that in all cases anion adsorption is involved to some extent in the deposition/dissolution processes of thallium. As will be shown later, a similar situation is found in the case of the irreversibly adsorbed thallium.

In order to obtain a deeper understanding of thallium deposition on $\operatorname{Pt}(111)$, the UPD of thallium was carried out in different concentrations of sulphate, different $\mathrm{pH}$ 's and also different concentrations of thallium. Figure 2 shows the voltammetric behaviour of the $\operatorname{Pt}(111)$ electrode in $0.1 \mathrm{M} \mathrm{H}_{2} \mathrm{SO}_{4}(\mathrm{pH}=1)$ with different concentrations of thallium in the solution. As can be observed, the peak at lower potentials (peak III) shifts from $0.19 \mathrm{~V}$ to $0.27 \mathrm{~V}$ when the concentration of thallium increases from $10^{-4} \mathrm{M}$ to $10^{-2} \mathrm{M}$. The displacement is ca. $60 \mathrm{mV}$ per unit of thallium concentration, which is the expected value for the redox process $\mathrm{Tl} / \mathrm{Tl}^{+}$. The same value is obtained in the positive shift of the peak at potentials above $0.6 \mathrm{~V}$ (peak I). In both cases the charge under the peak remains constant. On the other hand the spike potential associated to sulphate adsorption (at potentials close to $0.52 \mathrm{~V}$, peak II) is little affected by the concentration of thallium. These results suggest that the processes related to the peaks at lower and higher potentials involve the adsorption of thallium. On the other hand, the fact that the spike potential remains largely unaffected suggests that sulphate adsorption does not involve a significant change in thallium coverage.

Effects of the sulphate concentration in the process are examined in Figure 3, where the voltammetric profiles of the $\mathrm{Pt}$ (111) electrode at $\mathrm{pH}=1$ and $10^{-3} \mathrm{M}$ of thallium in solution are examined for two different concentrations of sulphate. As can be seen, peaks III and I are little affected by the concentration of sulphate, suggesting that these processes 
do not involve a significant change in sulphate coverage. However the spike potential decreases with increasing sulphate concentration, as expected for a sulphate adsorption/desorption process, and it is observed for the bare Pt (111) surface. ${ }^{28-30}$

Others species that could potentially contribute to the voltammogram of thallium modified Pt (111) are hydrogen and $\mathrm{OH}$ adsorption. These processes can be studied by analysing the effect of $\mathrm{pH}$ on the voltammograms. Previous works from Clavilier report the effect of the sulphuric acid concentration on the Tl UPD voltammogram. ${ }^{23}$ However, in these experiments, the $\mathrm{pH}$ and the sulphate concentrations are changed simultaneously, and therefore, it is difficult to separate both effects. Adzic et al. also studied the electrochemical behaviour of the thallium UPD on Pt (111) in $\mathrm{NaOH}$ media. ${ }^{22}$ In this study, the appearance of one unique peak at $-0.1 \mathrm{~V}$ vs NHE associated to the redox process $\mathrm{Tl} / \mathrm{Tl}^{+}$was observed. In the current work, we have studied the effect of $\mathrm{pH}$ on the UPD of Tl with constant sulphate concentration. Figure 4 shows the voltammetric profiles of $\operatorname{Pt}(111)$ in $0.1 \mathrm{M}$ of sulphate and $10^{-2} \mathrm{M}$ of $\mathrm{Tl}^{+}$as a function of the $\mathrm{pH}$. In order to remove the effect of $\mathrm{pH}$ on the reference electrode, these voltammograms are plotted using the NHE potential scale. It is worth mentioning that, on the bare $\mathrm{Pt}(111)$ electrode, hydrogen and $\mathrm{OH}$ adsorption processes shift by ca $-59 \mathrm{mV}$ per $\mathrm{pH}$ unit in the NHE scale, ${ }^{31}$ and therefore a similar dependence could be expected for hydrogen and $\mathrm{OH}$ adsorption on the thallium modified $\mathrm{Pt}(111)$ electrode. In addition, sulphate adsorption on the bare Pt (111) shows a small shift with $\mathrm{pH}^{32}$ The results in Figure 4 show that the voltammetric feature at $0.52 \mathrm{~V}$ shifts very little with $\mathrm{pH}$, indicating that this process does not involve hydrogen or $\mathrm{OH}$ adsorption, and is likely to be due to sulphate adsorption. It can also be seen that peak I increases the potential from 0.83 to $0.88 \mathrm{~V}$ as the $\mathrm{pH}$ is increased. This behaviour is difficult to 
understand, since both hydrogen and $\mathrm{OH}$ adsorption are expected to shift towards lower potentials as the $\mathrm{pH}$ increases.

Once the voltammetric features appearing in the Tl UPD process have been understood, the experiments to evaluate the irreversible adsorption process were carried out. In the irreversible adsorption process, the clean electrode was dipped in a solution containing thallium for a few seconds and then immersed in the electrochemical cell at 0.1 V. Figure 1A also shows the stable voltammetric profile of the $\mathrm{Pt}(111)$ electrode in $0.5 \mathrm{M}$ $\mathrm{H}_{2} \mathrm{SO}_{4}$ after the irreversible adsorption of thallium at saturation. As can be seen, the voltammogram of $\mathrm{Pt}(111)$ after thallium irreversible adsorption is quite similar to the voltammogram recorded for thallium underpotential deposition. It is also worth mentioning that the voltammogram obtained after thallium irreversible adsorption is stable during cycling, i.e., no significant changes are observed when the electrode is cycled many times within the potential limits shown in the figure, limits which include the peak for the $\mathrm{Tl} / \mathrm{Tl}^{+}$oxidation process. For typical UPD processes, such as copper on platinum or gold electrodes, after the $\mathrm{Cu} / \mathrm{Cu}^{2+}$ oxidation process, only a small fraction of copper atoms (those atoms that had no time to diffuse away from the interface region) are re-deposited in the subsequent negative scan. Thus, after two or three cycles, the profile for the clean electrode is recovered. In the case of the adatoms that adsorb irreversibly on the surface, the stability of the adatom on the surface after the oxidation process can be explained by different processes. In many cases, the oxidation leads to the formation of an oxide or a hydroxide compound with low solubility. ${ }^{2,5,33}$ For the case of thallium, the formation of such compounds is unlikely at this $\mathrm{pH}$. Alternatively, the stability of the oxidized thallium adsorbed on the surface could be tentatively ascribed to the formation of ion pairs with 
anions. Since anions are adsorbed at these potentials, thallium ions do not diffuse to the bulk solution and therefore, they can be reduced in the subsequent negative scan direction.

Another important characteristic of the voltammogram obtained after the irreversible adsorption of thallium is its similarity with the voltammogram obtained from the UPD process; however, the peak potentials are displaced with respect to those in the UPD process. We will first discuss the pair of peaks observed at potentials higher than 0.6 $\mathrm{V}$. For the UPD at $\left[\mathrm{Tl}^{+}\right]=10^{-2} \mathrm{M}$, the pair of peaks is centred at around $0.75 \mathrm{~V}$ and the charge under the peaks is $53 \pm 3 \mu \mathrm{Ccm}^{-2}$. For Tl irreversible adsorption the peaks are shifted by ca. $0.1 \mathrm{~V}$ towards more negative potentials but the charge remains very similar $\left(56 \pm 2 \mu \mathrm{Ccm}^{-2}\right)$. Therefore, the position of the peaks is closer to the Tl UPD at $\left[\mathrm{Tl}^{+}\right]=10^{-4} \mathrm{M}$ (see figure 2).

The second potential region, between, 0.3 and $0.6 \mathrm{~V}$, is associated to sulphate adsorption. The completion of the sulphate adlayer is characterized by a sharp spike related to an order/disorder phase transition. ${ }^{23}$ The potential position of the spike is different in the three cases $(0.45 \mathrm{~V}$ for the bare $\mathrm{Pt}(111)$ surface, $0.47 \mathrm{~V}$ in the irreversible adsorption and $0.49 \mathrm{~V}$ in the UPD with $\left.\left[\mathrm{Tl}^{+}\right]=10^{-2} \mathrm{M}\right)$. Another remarkable difference is the magnitude of the current density of the spikes. In the case of the irreversible adsorption, the maximum of the current density of the peak $\left(192 \mu \mathrm{Acm}^{-2}\right)$ is more than two times the peak in the UPD process $\left(82 \mu \mathrm{Acm}^{-2}\right)$ and three times the current density of the spike of the $\operatorname{Pt}(111)$ in the absence of thallium $\left(64 \mu \mathrm{Acm}^{-2}\right)$. In order to explain these differences, the charges associated to these processes have been calculated by integrating the positive scan and using a zero baseline (see inset in Figure 1A). As can be seen, the charge associated to sulphate adsorption is the same in the bare platinum, the irreversible adsorption and the UPD process $\left(79 \pm 4 \mu \mathrm{Ccm}^{-2}\right)$. However, the charge associated to the spike is higher in the 
case of the irreversible adsorption process. This fact may be tentatively ascribed to a different degree of surface ordering in the presence of thallium irreversibly adsorbed. It could be argued that in the presence of thallium irreversibly adsorbed, the adsorption of sulphate is more disordered during the first stage of sulphate adsorption (i.e., at potentials before the spike), and, as a result, a lower sulphate coverage is achieved at these potentials. Since the spike corresponds to a transition to an ordered $\sqrt{ } 3 x \sqrt{7}$ structure with a higher sulphate coverage, therefore, a higher amount of sulphate would be need to be adsorbed during the spike in order to reach this structure in the presence of thallium irreversibly adsorbed. This would also explain the displacement to lower potentials.

The last potential region, between 0.05 and $0.3 \mathrm{~V}$, is characterized by a diminution of the current density due to suppression of the hydrogen adsorption in the presence of thallium. Also, a small and well-defined pair of peaks appears around $0.13 \mathrm{~V}$ in the case of Tl irreversibly adsorbed. These peaks can be compared with the peaks observed in the underpotential deposition at $0.2 \mathrm{~V}$. It should be noted that these small peaks are very sensitive to the presence of defects on the Pt (111) surface, which suggest that they are related to a phase transition in the thallium adlayer.

When the upper potential limit is set above $0.8 \mathrm{~V}$, the desorption of the irreversibly adsorbed $\mathrm{Tl}$ takes place (Figure 5). In successive cycles, the current density of the peak due to the redox process $\mathrm{Tl} / \mathrm{Tl}^{+}$diminishes and the potential position moves toward negative potentials. The charge during the first 25 cycles is almost constant, and after that, the charge diminishes significantly. This indicates that thallium desorption is not diffusion controlled but kinetically controlled, with lower desorption rates near point of saturated coverage. After 23 cycles, a new sharp peak appears in the negative scan at $0.6 \mathrm{~V}$ and 
increases in the next successive cycles. For cycles up to 25, the peak diminished and becomes wider. This coincides with the diminution of the charge in the positive sweep. Simultaneously, a little sharp peak appears in the positive sweep and remains for a few cycles. After that, both peaks disappear. It is important to note that the voltammetric profile of the bare Pt (111) electrode is not recovered. This fact indicates that some thallium remains on the surface after more than 50 cycles. The complex evolution of the voltammogram upon desorption of thallium clearly suggests that the interactions between $\mathrm{Pt}(111)$, thallium and sulphate depend on the thallium coverage and that some synergistic effects can be observed at intermediate coverage. Similar results were reported by Abd El Meguid et al., ${ }^{25}$ by studying the controlled desorption of thallium from $\operatorname{Pt}(332)$ and $\operatorname{Pt}(775)$. In addition, a similar behaviour has been observed for adsorbed copper with low coverage on platinum single crystals, where adsorption of anions on platinum sites is favoured by the presence of a neighbouring copper atom..$^{34,35}$

The effect on the irreversible adsorption of thallium on $\mathrm{Pt}(111)$ stepped surface was also studied. Two types of stepped surfaces were studied, with (110) and (100) step symmetry, respectively. The stepped surfaces belonging to the series of $\operatorname{Pt}(\mathrm{S})[(\mathrm{n}-$ $1((111) \times(100)]$ have Miller indices $\operatorname{Pt}(n, n, n-2)$ and the stepped surfaces belonging to the series $\operatorname{Pt}(\operatorname{S})[n(111) \times(100)]$ have Miller indices $\operatorname{Pt}(n+1, n-1, n-1)$. Figure 6 show the voltammetric profiles obtained after thallium irreversible adsorption at saturation. In both series it can be seen that the electrochemical behaviour of the stepped surfaces is similar to that obtained for $\operatorname{Pt}(111)$. The same redox processes are observed, but the charge under the peaks decreases with increasing the step density. Moreover, the height of the spike related to the sulphate order/disorder transition diminishes significantly, as observed on the unmodified surfaces, which clearly indicates that this process is related to an order/disorder 
transition in the sulphate adlayer. In addition, the charge under the $\mathrm{Tl} / \mathrm{Tl}^{+}$process at ca $0.7 \mathrm{~V}$ decreases as the step density is increased. This suggest that the value of charge on the $\mathrm{Tl} / \mathrm{Tl}^{+}$process could be used to quantify the amount of (111) surface domains in a polycrystalline electrode or a nanoparticle sample ${ }^{36}$ as has been previously done with other probes, such as $\mathrm{Bi}^{4}$ and $\mathrm{Te}^{2}$.

\subsection{Electrochemical behavior of UPD and irreversibly adsorbed thallium on Pt (111) in perchlorate solutions}

Figure 1B shows the voltammetric profiles of the $\mathrm{Pt}(111)$ electrode totally covered by thallium adatoms irreversibly adsorbed in $0.1 \mathrm{M} \mathrm{HClO}_{4}$ and the UPD of thallium in 0.1 $\mathrm{M} \mathrm{HClO}_{4}+10^{-2} \mathrm{M}$ of $\mathrm{Tl}$. In the first potential region between 0.8 and $1 \mathrm{~V}$, there are two pair of peaks attributed to the redox process of $\mathrm{Tl} / \mathrm{Tl}^{+}$. The pair of peaks appears in both the UPD and the irreversible adsorption, however in the irreversible adsorption of thallium, these peaks appear at ca. $0.1 \mathrm{~V}$ more negative potentials. The charge associated to the process is the same (within experimental error): $62 \pm 3 \mu \mathrm{Ccm}^{-2}$, and it is also very similar to the charge in sulphuric acid: $60 \pm 3 \mu \mathrm{Ccm}^{-2}$. The differences can probably be ascribed to double layer correction. Therefore one can assume that the coverage in both cases is the same and hence, the comparison of both profiles is meaningful.

The second potential region, between 0.6 and $0.8 \mathrm{~V}$, is characterized by the presence of a pair of sharp peaks at $0.67 \mathrm{~V}$ in the irreversible adsorbed layer and $0.65 \mathrm{~V}$ in UPD process. The displacement of this pair of peaks in the irreversible adsorption system towards a more positive potential with respect to the UPD system is opposite to the direction of the shift of the other peaks in the voltammograms. Similar to the region at 
higher potentials, the maximum current density is lower in the irreversible adsorption, but the charge associated to the process is the same in both cases $\left(78 \pm 3 \mu \mathrm{Ccm}^{-2}\right)$. By using SNIFTIRS, Markinovic et al. attributed this peak to the adsorption of ionic pairs of thallium with perchlorate anions on the surface. ${ }^{21}$ However, it is unlikely that the species responsible for the charge transfer are perchlorate ions; therefore, $\mathrm{OH}$ adsorption can be tentatively proposed (as is usually done for the bare $\mathrm{Pt}$ (111) surface)

The last potential region is also characterized by a pair of small peaks which appear at $0.18 \mathrm{~V}$ in the case of the UPD, and $0.25 \mathrm{~V}$ in the case of the irreversible adsorption.

In order to obtain information regarding the species that participate in each of the processes, the Tl UPD was studied in $0.1 \mathrm{M} \mathrm{HClO}_{4}$ as a function of the concentration of the species in solution (Figure 7a). It can be observed that when the concentration of thallium is increased the from $10^{-4} \mathrm{M}$ to $10^{-3} \mathrm{M}$, peaks I and III move towards positive potentials; the shift is ca. $60 \mathrm{mV}$ per unit in the concentration of thallium, as expected for a thallium deposition process.

On the other hand, the potential of peak II, at around $0.6 \mathrm{~V}$, only increases slightly with the thallium concentration. Similar behaviour was observed when the experiments were performed at $\mathrm{pH}=3$. As was mentioned before, infrared experiments suggest that the peak II is associated to the ionic pairs $\mathrm{Tl}-\mathrm{ClO}_{4}$, but if that were the case, a significant shift in the voltammetric peak, as a function of the concentration of thallium and perchlorate, should have been observed. In view of the present results, we can conclude that the peak at around $0.6 \mathrm{~V}$ does not involve a significant change in coverage of thallium. In order to elucidate if peak II involves the adsorption of perchlorate, we measured the voltammogram at two concentrations of perchloric anions (at constant $\mathrm{pH}$ and concentration of thallium). 
The results, given in Figure $7 \mathrm{~B}$, show that the peak II is not much affected by the concentration of perchlorate, suggesting that the peak II is not associated to any process that involves perchlorate anion adsorption. In conclusion, we have shown that peak II does not involve the adsorption of thallium or perchlorate. Thus, o this process can be tentatively ascribed to the adsorption/desorption of $\mathrm{OH}$. In order to validate the hypothesis, UPD experiments were performed at constant concentration of thallium and perchlorate while varying the $\mathrm{pH}$ of the solution (Figure 8). As before, in order to remove the effect of $\mathrm{pH}$ on the reference electrode, these voltammograms are plotted in the SHE potential scale. It can be seen that peaks I and III do not shift with the $\mathrm{pH}$. On the other hand, peak II moves ca. $60 \mathrm{mV}$ per $\mathrm{pH}$ unit toward negative potentials, indicating that this process is due to $\mathrm{OH}$ adsorption.

In order to better understand the process that occurs during the irreversible adsorption of thallium on the $\operatorname{Pt}(111)$ surface, the desorption of the thallium is induced when the electrodes cycled up to at $0.95 \mathrm{~V}$. The resulting profiles are shown in Figure 9. As the desorption of $\mathrm{Tl}$ takes places within the cycling process, the sharp peak at $0.65 \mathrm{~V}$ becomes smaller and broader and shifts towards positive potentials. Interestingly, the shift of the peak is in opposite direction to the shift observed in Figure 2 for the same process in sulphuric acid. Meanwhile, the current density of peak III at $0.18 \mathrm{~V}$ is diminished and moves toward negative potentials, disappearing altogether after just 6 cycles. When the peak in the potential region III disappeared, the current density between 0.05 and $0.4 \mathrm{~V}$ increased. Such current increase is related to the adsorption/desorption of hydrogen on the free platinum sites. Also, peak I diminishes, becomes broader and moves toward negative potentials. After several sweeps, a pair of reversible peaks, associated to the adsorption/desorption of the $\mathrm{OH}$ species on the free sites of platinum, appear at $0.81 \mathrm{~V}$ and 
increase in the next successive cycles. After several cycles, the shape of the voltammetric profile is very similar to the $\mathrm{Pt}$ (111) in perchloric acid in absence of thallium, but a small amount of thallium remains on the surface.

Similar to the process described in previous section, the stepped surfaces belonging to the series of $\operatorname{Pt}(\mathrm{S})[\mathrm{n}(111) \times(111)]$ having Miller indices $\operatorname{Pt}(\mathrm{n}, \mathrm{n}, \mathrm{n}-2)$ and $\operatorname{Pt}(\mathrm{S})[\mathrm{n}(111) \times(100)]$ having Miller indices $\operatorname{Pt}(\mathrm{n}+1, \mathrm{n}-1, \mathrm{n}-1)$ were used in order to study the effect of the step density in the irreversibly adsorbed thallium-modified electrodes in perchloric acid solutions. Figure 10 shows the voltammetric profiles of thallium irreversibly adsorbed on the stepped electrodes vicinal to the $\mathrm{Pt}(111)$ pole in $0.1 \mathrm{M} \mathrm{HClO}_{4}$. In both series, it can be seen that the electrochemical behaviour of the stepped surfaces is similar to that obtained for the Pt (111). The peak positions and the charge strongly depend on the step density. Peak I becomes smaller (and comprises less charge) as the terrace length diminishes for the series of electrodes Pt $(n, n, n-2)$. It is also important to note the significant change in the irreversibility of the peak as a function of the terrace width. Even though such a change might indicate the desorption of the species, the voltammograms of the Pt $(n, n, n-2)$ series are stable on consecutive cycles. Peak III disappears in both series of step surfaces, which is an indication that this process strongly depends on the long-range order. On the other hand, the charge associated to the spike in region II decreases as the terrace length diminishes. In addition, the peak shifts toward positive potentials and disappears when the number of atoms in the terrace is less than 6. The stability of thallium irreversibly adsorbed on the series $\mathrm{Pt}(\mathrm{n}+1, \mathrm{n}-1, \mathrm{n}-1)$ is compromised at the upper limit potential, therefore the more positive potential was limited to $0.9 \mathrm{~V}$. As in the Pt (n,n n-2) case, the charge associated to the process in region II decreases as a function of the step density and, at the same time, the peak shifts towards more positive potentials. 


\section{Conclusions.}

The underpotential deposition of thallium on $\mathrm{Pt}(111)$ and on vicinal step surfaces has been investigated, and a detailed analysis of the dependence of three characteristic voltammetric features as a function of $\mathrm{pH}$, the nature and concentration of the anion $\left(\mathrm{HClO}_{4}\right.$ and $\left.\mathrm{H}_{2} \mathrm{SO}_{4}\right)$ and the concentration of thallium is presented. In addition, for the first time, the electrochemical behaviour of thallium irreversibly adsorbed on $\operatorname{Pt}(111)$ and on platinum stepped surfaces composed of (111) terraces and monoatomic steps has been described. As shown by the results obtained with the platinum step surfaces, this reaction is a promising probe for the quantitative characterization of (111) surface domains on the platinum surface. 


\section{Figure Captions.}

Figure 1. Voltammetric profile of the $\mathrm{Pt}$ (111) electrode in (A) $0.5 \mathrm{M} \mathrm{H}_{2} \mathrm{SO}_{4}$ and (B) $0.1 \mathrm{M}$

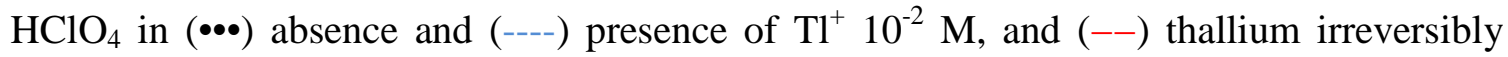
adsorbed $v=50 \mathrm{mVs}^{-1}$. Inset in (A): Plot of the total charge as a function of the potential; $. v=50 \mathrm{mVs}^{-1}$.

Figure 2. Voltammetric profile of the $\mathrm{Pt}$ (111) electrode at $0.1 \mathrm{M} \mathrm{H}_{2} \mathrm{SO}_{4}$ and at different concentrations of $\mathrm{Tl}^{+} .(-) \mathrm{Tl}^{+} 10^{-4} \mathrm{M},(-----) \mathrm{Tl}^{+} 10^{-3} \mathrm{M}$ and $\left({ }^{(\cdots \cdots \cdots \cdots)}\right) \mathrm{Tl}^{+} 10^{-2} \mathrm{M} ; . \mathrm{v}=50$ $\mathrm{mVs}^{-1}$.

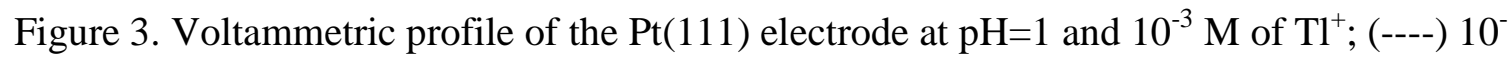
${ }^{3} \mathrm{M}$ of sulphate and (-) $0.1 \mathrm{M}$ of sulphate. $\mathrm{v}=50 \mathrm{mVs}^{-1}$.

Figure 4. Voltammetric profile of $\mathrm{Pt}$ (111) electrode in presence of $\mathrm{Tl}^{+} 10^{-4} \mathrm{M}$ and $0.1 \mathrm{M}$ $\mathrm{SO}_{4}{ }^{2-}$ at different $\mathrm{pH}^{\prime} \mathrm{s} .(-) \mathrm{pH}=1 ;(----) \mathrm{pH}=1.7 ;(\cdots \cdots \cdots) \mathrm{pH}=2.3$ and $\left({ }^{(\cdots \cdots \cdots \cdots)} \mathrm{pH}=3 . \mathrm{v}=50\right.$ $\mathrm{mVs}^{-1}$.

Figure 5. Consecutive voltammetric profiles of the Tl-modified Pt (111) in $0.5 \mathrm{M} \mathrm{H}_{2} \mathrm{SO}_{4}$. Only the cycles $1,13,27$ and 34 are shown for the sake of clarity. Inset: Zoom in the potential region between $0 \mathrm{~V}$ and $0.2 \mathrm{~V}$ vs RHE. $\mathrm{v}=50 \mathrm{mVs}^{-1}$. The arrows indicate the direction of increasing cycling number. 
Figure 6. Voltammetric profiles of $\operatorname{Pt}(n, n, n-2)$ electrodes (A) and $\operatorname{Pt}(n+1, n-1, n-1)$ electrodes (B) covered with irreversibly adsorbed thallium. Electrolyte: $0.5 \mathrm{M} \mathrm{H}_{2} \mathrm{SO}_{4} . \mathrm{v}=50 \mathrm{mVs}^{-1}$.

Figure 7. A) Voltammetric profile of the $\mathrm{Pt}(111)$ electrode at $0.1 \mathrm{M} \mathrm{HClO}_{4}$ at different concentrations of $\mathrm{Tl}^{+}$as indicated in the figure. B) Voltammetric profile of the $\operatorname{Pt}(111)$ electrode in $(-) 0.01 \mathrm{M} \mathrm{HClO}_{4}+10^{-2} \mathrm{M} \mathrm{KClO}_{4}+10^{-3} \mathrm{M}$ of $\mathrm{Tl}^{+}$and $(-) 0.01 \mathrm{M}$ $\mathrm{HClO}_{4}+0.1 \mathrm{M} \mathrm{KClO}_{4}+10^{-3} \mathrm{M}$ of $\mathrm{Tl}^{+} . v=50 \mathrm{mVs}^{-1}$.

Figure 8. Voltammetric profile of the $\mathrm{Pt}(111)$ electrode in (-----) $0.1 \mathrm{M} \mathrm{KClO}_{4}+10^{-3} \mathrm{M}$

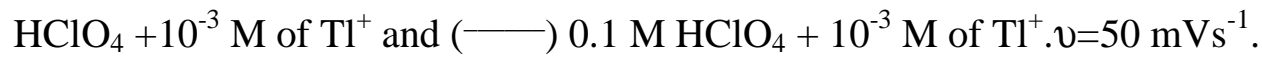

Figure 9. Consecutive voltammetric profiles of the Tl-modified $\mathrm{Pt}(111)$ in $0.1 \mathrm{M} \mathrm{HClO}_{4}$; $. v=50 \mathrm{mVs}^{-1}$. The arrows indicate the direction of increasing cycling number.

Figure 10. Voltammetric profiles of $\operatorname{Pt}(n, n, n-2)$ electrodes (A) and $\operatorname{Pt}(n+1, n-1, n-$ 1)electrodes (B) covered with irreversibly adsorbed thallium in $0.1 \mathrm{M} \mathrm{HClO}_{4}$. Scan rates: 50 $\mathrm{mV} \mathrm{s}^{-1}$. 

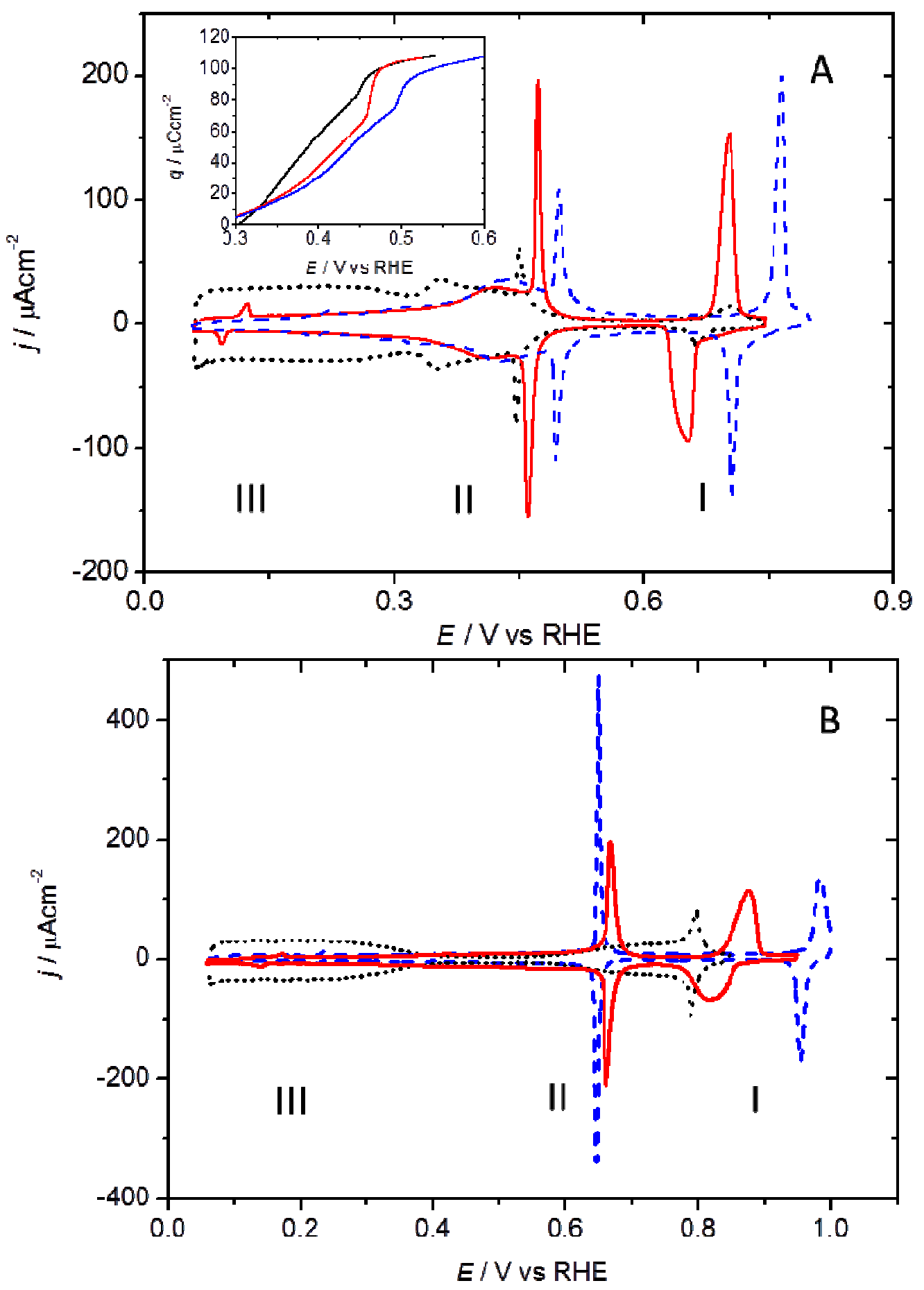

Figure 1. 


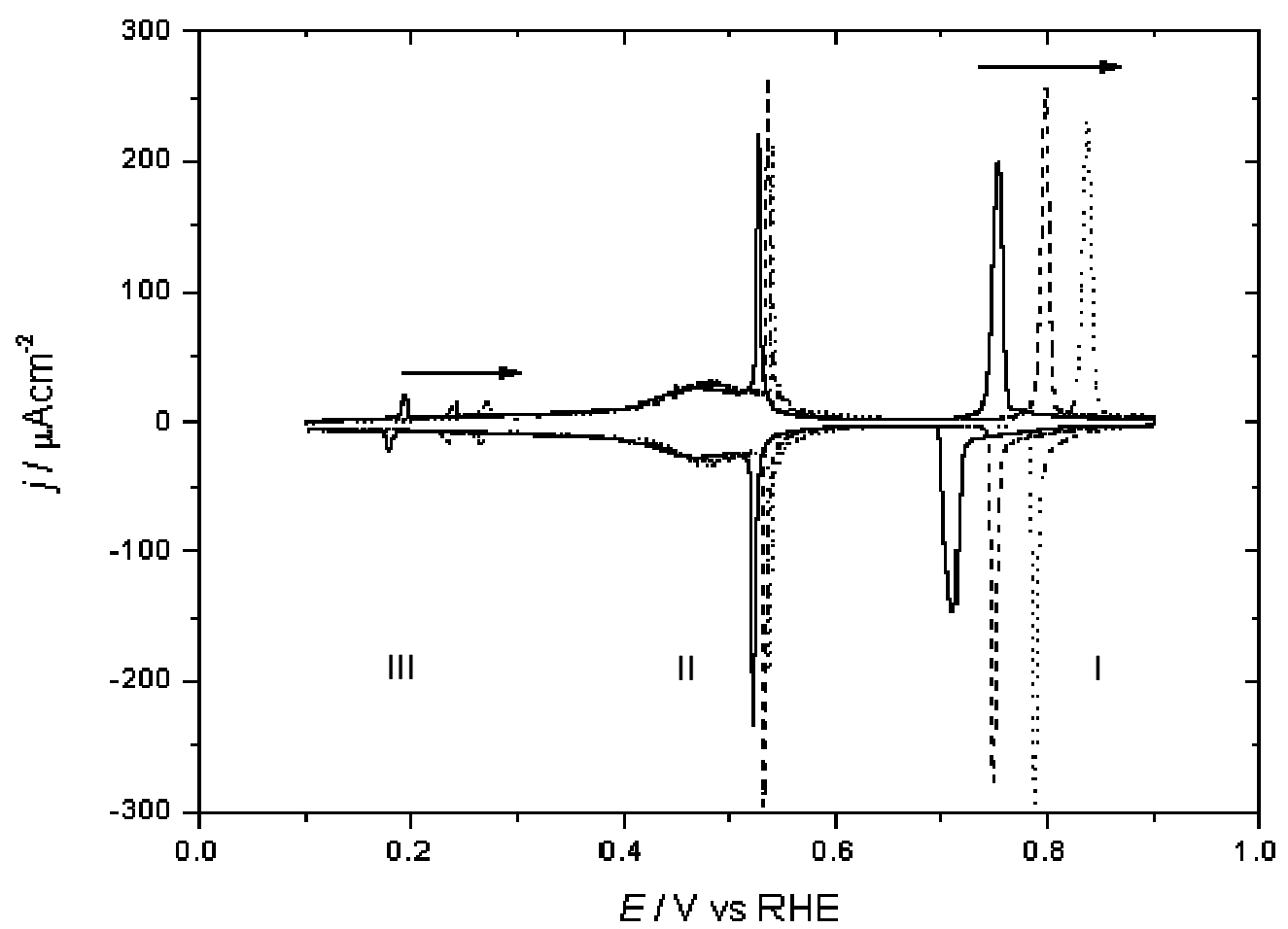

Figure 2. 


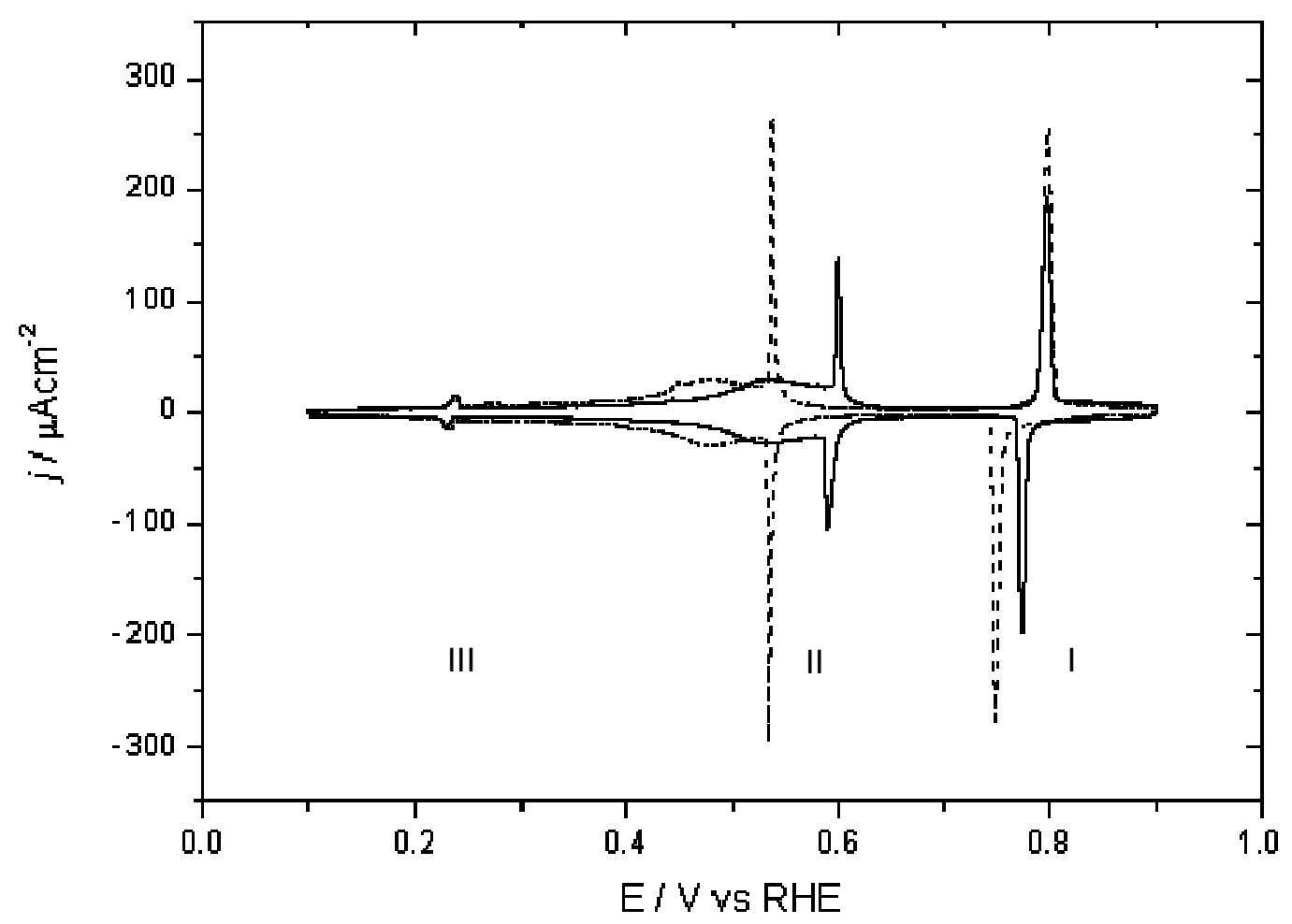

Figure 3. 


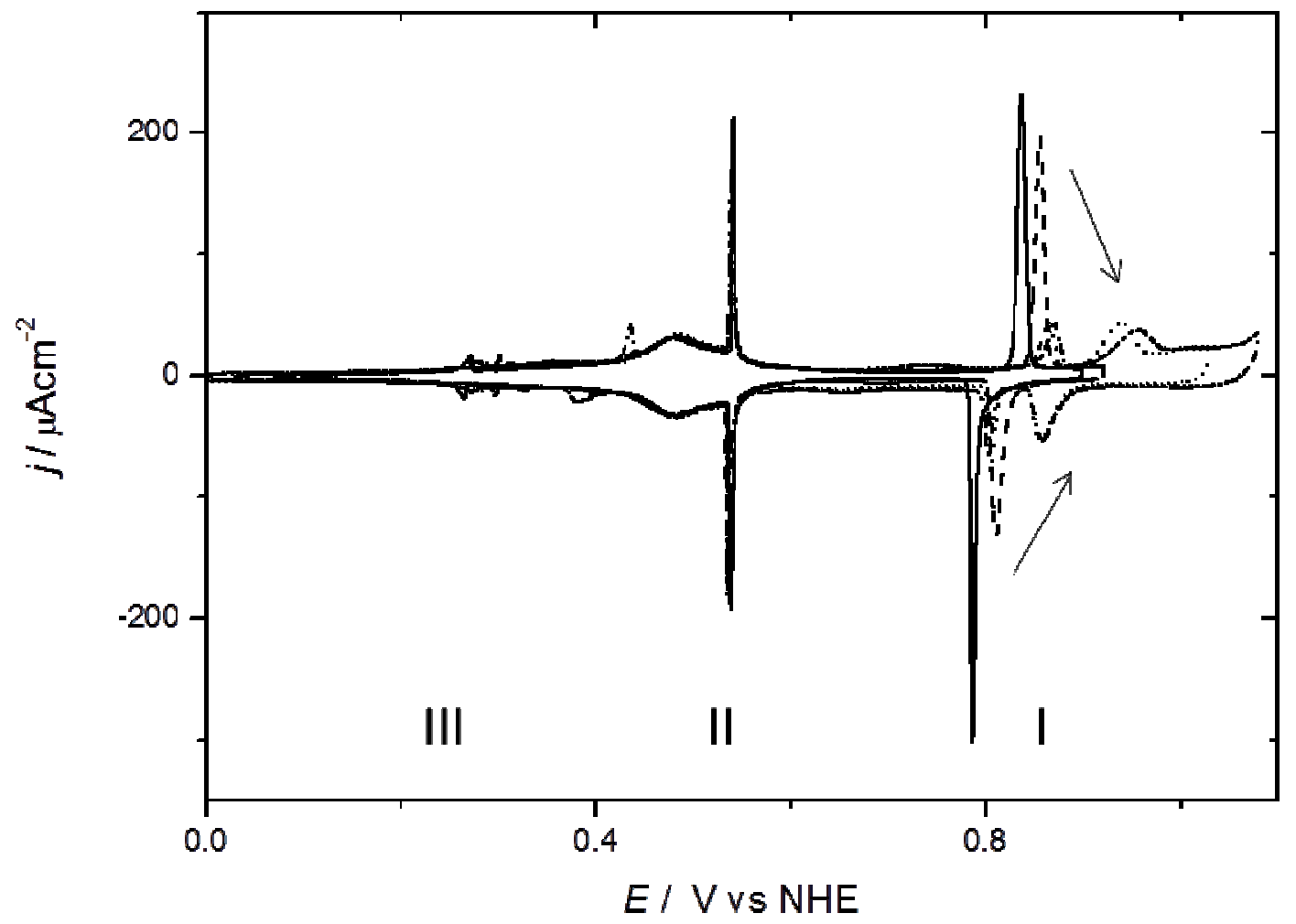

Figure 4. 


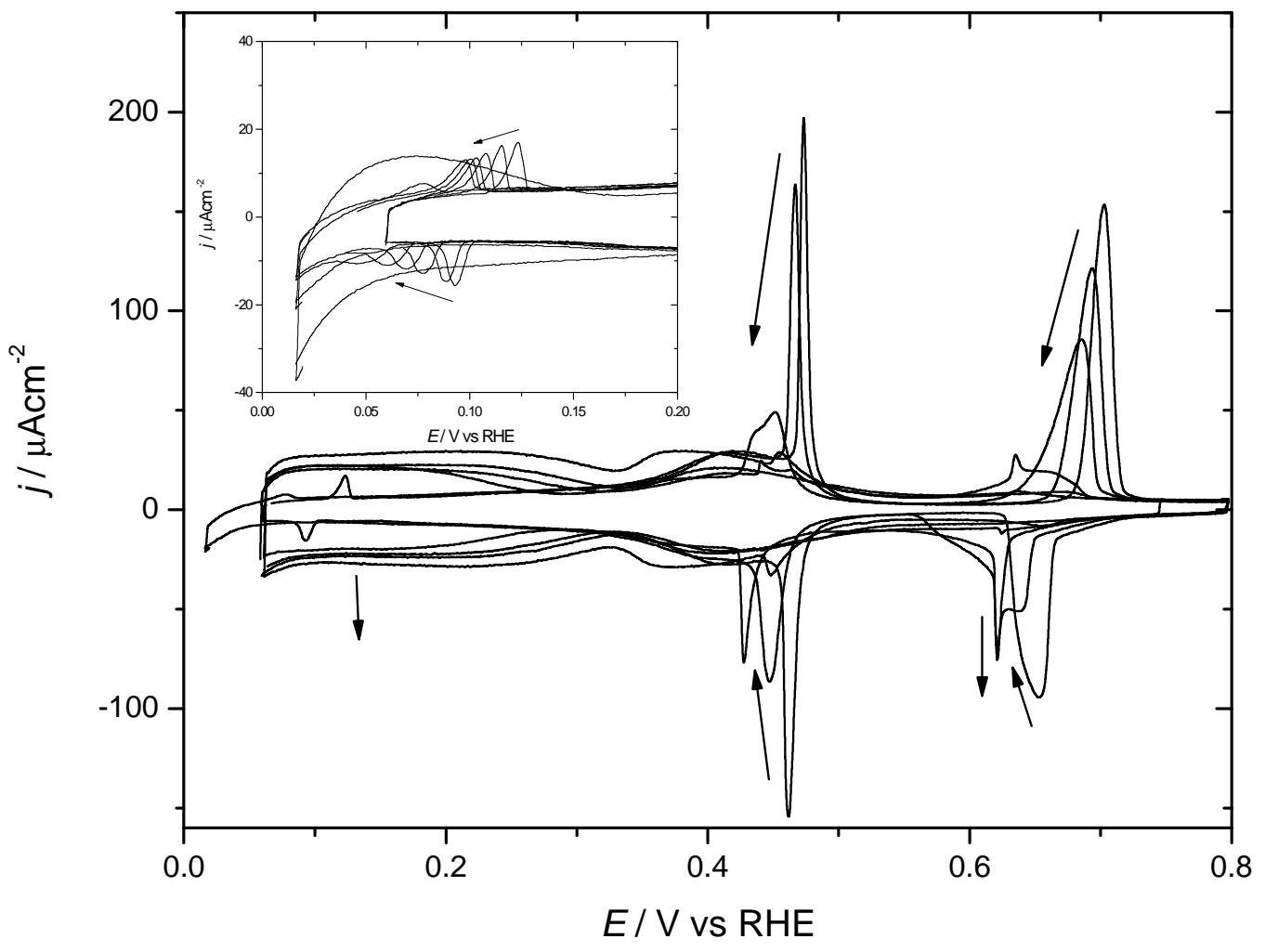

Figure 5. 

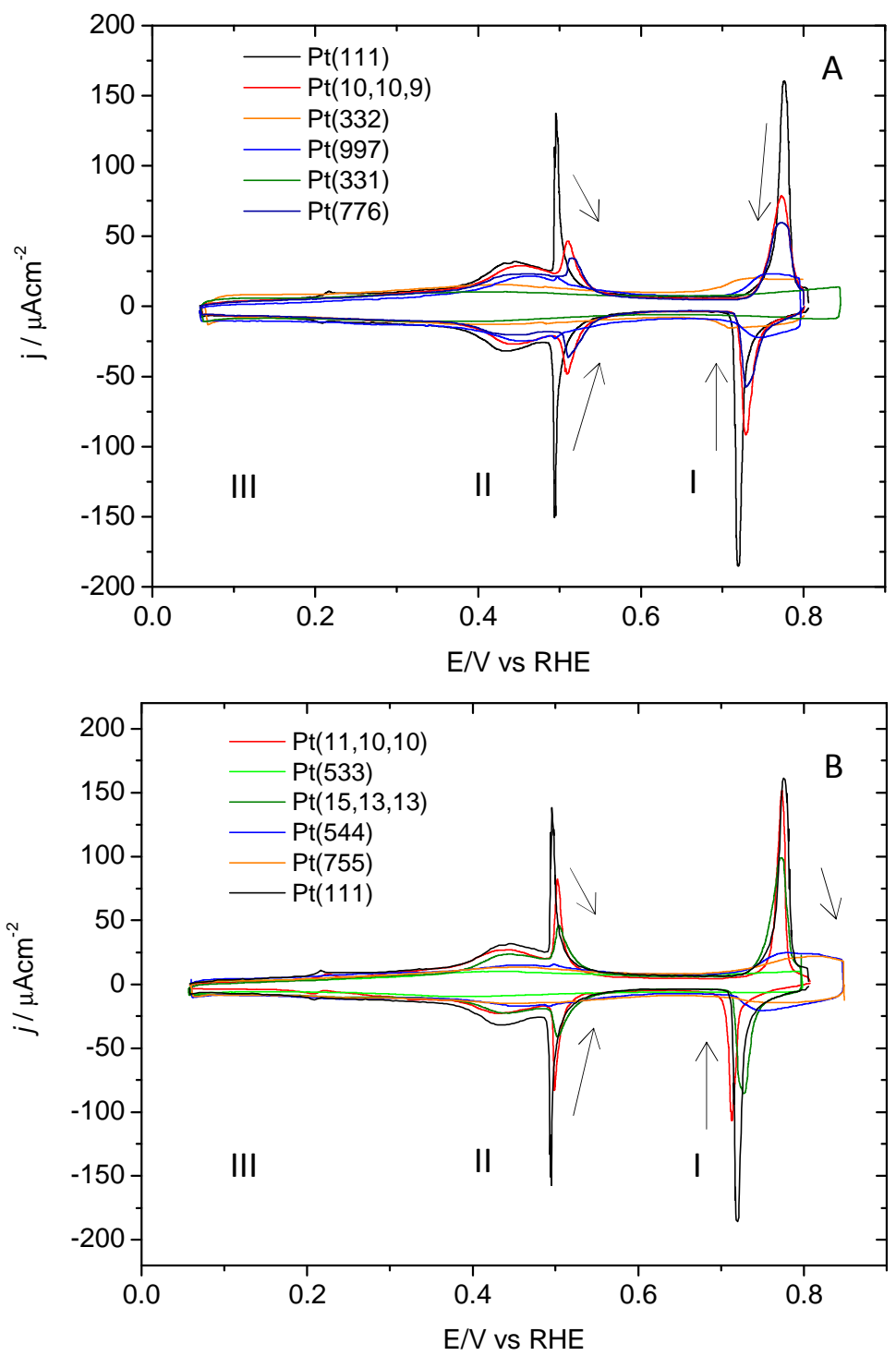

Figure 6. 

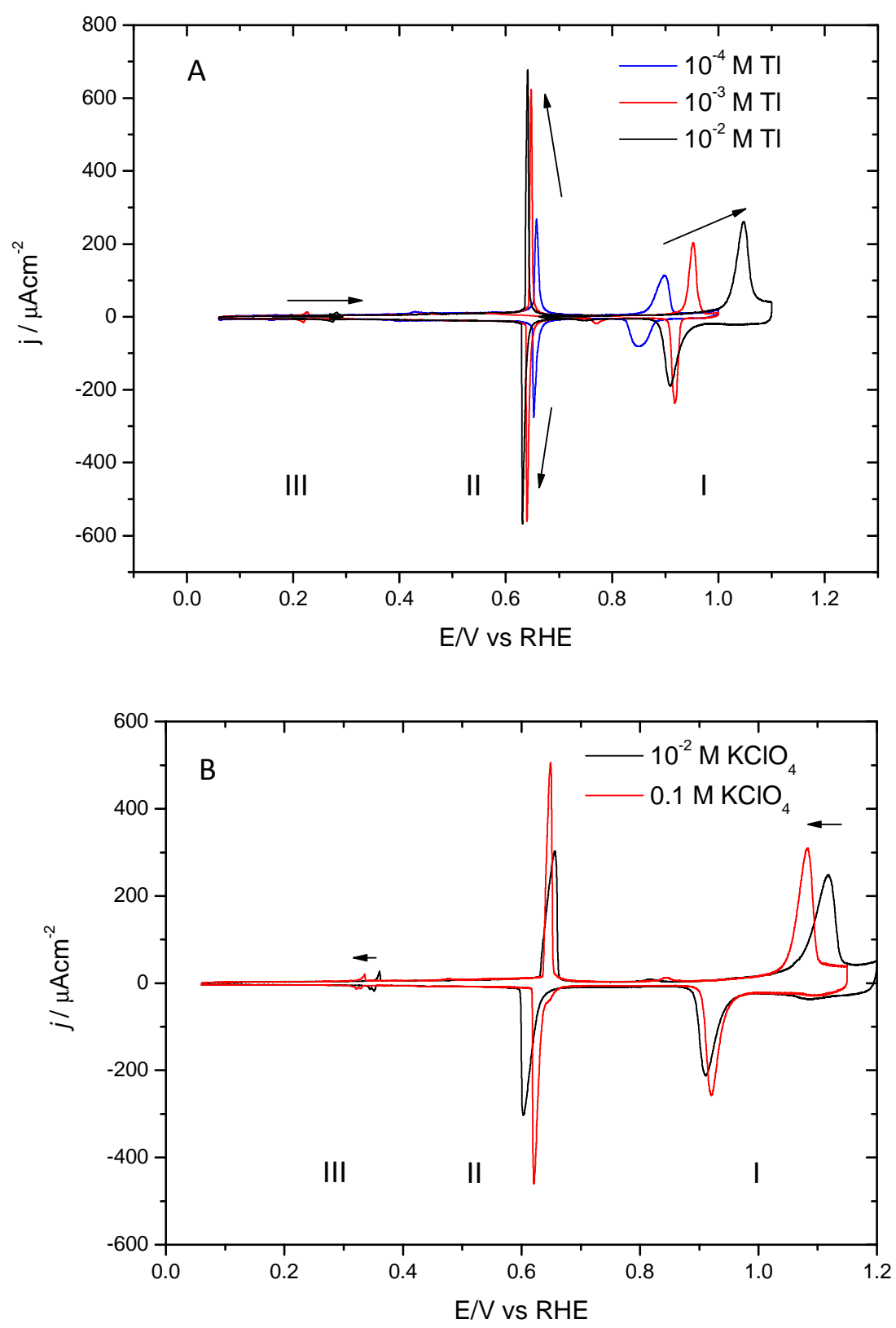

Figure 7. 


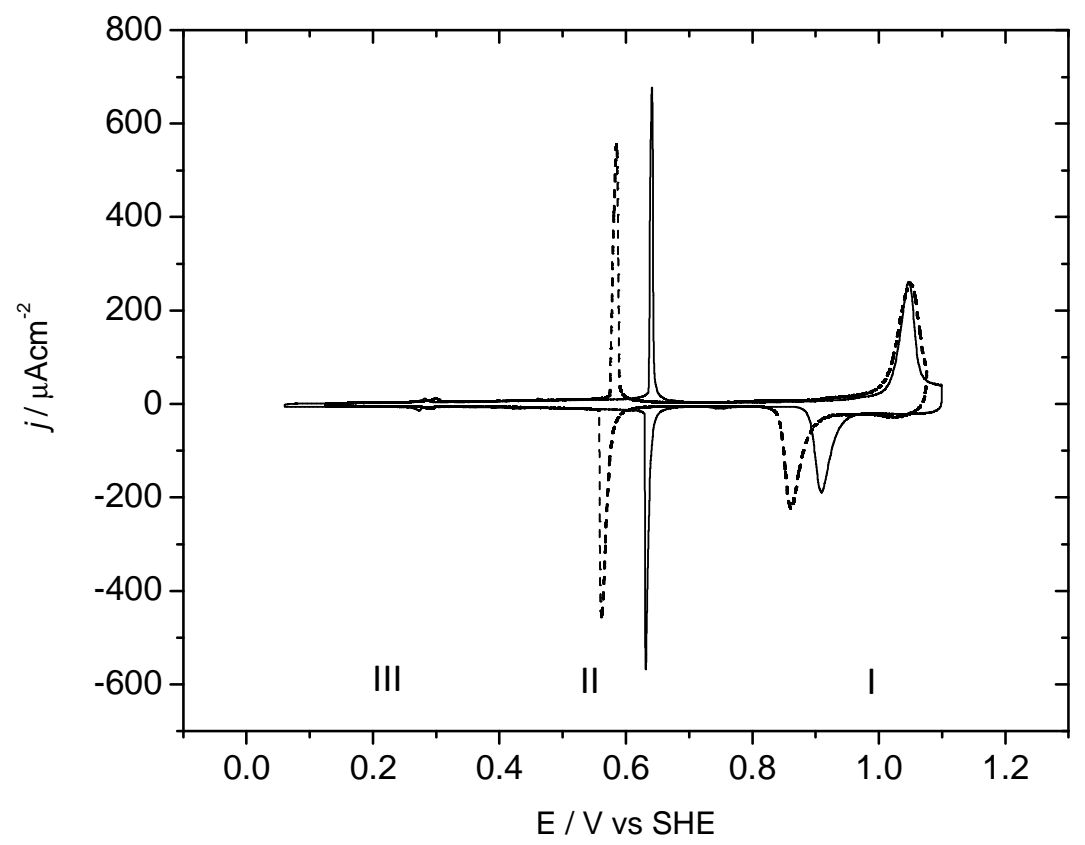

Figure 8. 

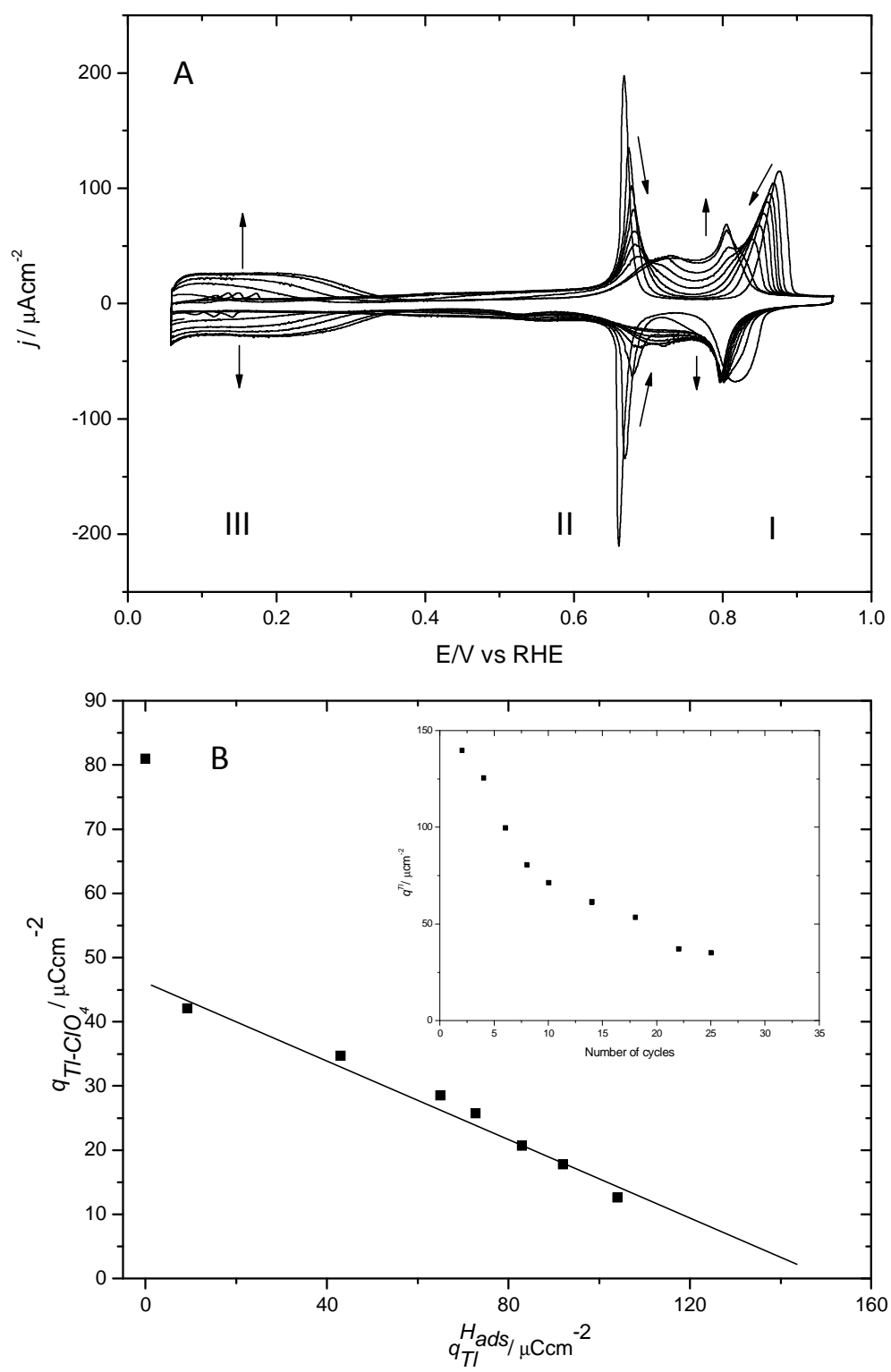

Figure 9. 

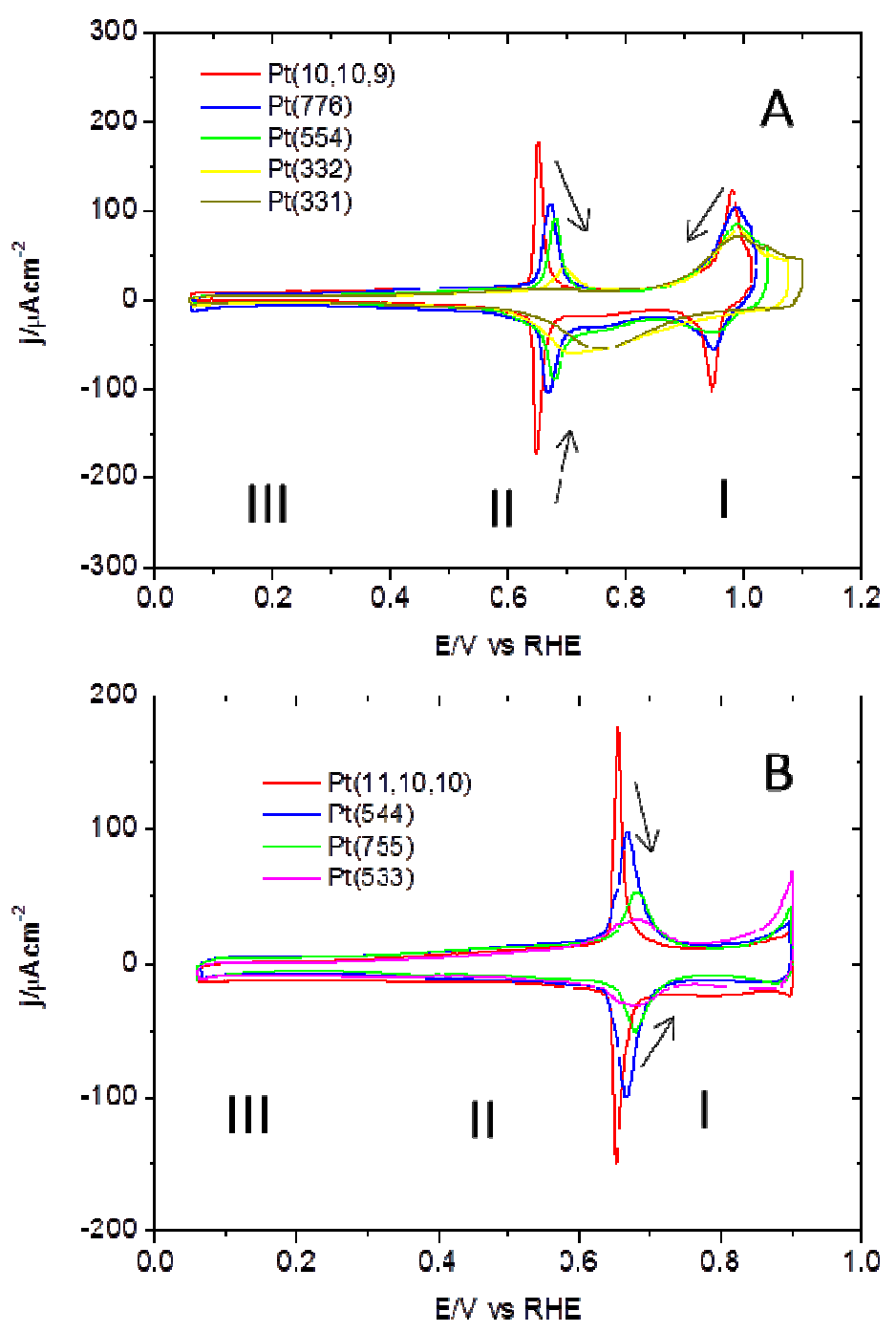

Figure 10. 
(1) Herrero, E.; Buller, L. J.; Abruña, H. D. Chemical Reviews 2001, 101, 1897.

(2) Rodríguez, P.; Herrero, E.; Aldaz, A.; Feliu, J. M. Langmuir 2006, 22,

10329.

(3) Rodriguez, P.; Herrero, E.; Solla-Gullón, J.; Vidal-Iglesias, F. J.; Aldaz, A.; Feliu, J. M. Electrochimica Acta 2005, 50, 3111.

(4) Rodríguez, P.; Solla-Gullón, J.; Vidal-Iglesias, F. J.; Herrero, E.; Aldaz, A.; Feliu, J. M. Analytical Chemistry 2005, 77, 5317.

(5) Clavilier, J.; Feliu, J. M.; Aldaz, A. Journal of Electroanalytical Chemistry and Interfacial Electrochemistry 1988, 243, 419.

(6) Chrzanowski, W.; Kim, H.; Wieckowski, A. Catalysis Letters 1998, 50, 69.

(7) Chrzanowski, W.; Wieckowski, A. Langmuir 1997, 13, 5974.

(8) Johnston, C. M.; Strbac, S.; Wieckowski, A. Langmuir 2005, 21, 9610.

(9) Johnston, C. M.; Strbac, S.; Lewera, A.; Sibert, E.; Wieckowski, A. Langmuir 2006, 22, 8229.

(10) Gómez, R.; Llorca, M. J.; Feliu, J. M.; Aldaz, A. Journal of Electroanalytical Chemistry 1992, 340, 349.

(11) Shi, Z.; Wu, S.; Lipkowski, J. Electrochimica Acta 1995, 40, 9.

(12) Mrozek, P.; Sung, Y.-e.; Han, M.; Gamboa-aldeco, M.; Wieckowski, A.;

Chen, C.-h.; Gewirth, A. A. Electrochimica Acta 1995, 40, 17.

(13) Pobelov, I.; Nagy, G.; Wandlowski, T. J Chem Sci 2009, 121, 745.

(14) Abruña, H. D.; Feliu, J. M.; Brock, J. D.; Buller, L. J.; Herrero, E.; Li, J.;

Gómez, R.; Finnefrock, A. Electrochimica Acta 1998, 43, 2899.

(15) Herrero, E.; Glazier, S.; Buller, L. J.; Abruña, H. D. Journal of

Electroanalytical Chemistry 1999, 461, 121.

(16) Herrero, E.; Buller, L. J.; Li, J.; Finnefrock, A. C.; Salomón, A. B.; Alonso,

C.; Brock, J. D.; Abruña, H. D. Electrochimica Acta 1998, 44, 983.

(17) Palomar-Pardavé, M.; González, I.; Batina, N. The Journal of Physical Chemistry B 2000, 104, 3545.

(18) Leiva, E. Electrochimica Acta 1996, 41, 2185.

(19) Gordon, J. G.; Melroy, O. R.; Toney, M. F. Electrochimica Acta 1995, 40, 3.

(20) Stickney, J. L.; Rosasco, S. D.; Hubbard, A. T. Journal of the

Electrochemical Society 1984, 131, 260.

(21) Markinovic, N. S.; Fawcett, W. R.; Wang, J. X.; Adzic, R. R. The Journal of Physical Chemistry 1995, 99, 17490.

(22) Adžić, R. R.; Wang, J. X.; Magnussen, O. M.; Ocko, B. M. The Journal of Physical Chemistry 1996, 100, 14721.

(23) Clavilier, J.; Ganon, J.-P.; Petit, M. Journal of Electroanalytical Chemistry and Interfacial Electrochemistry 1989, 265, 231.

(24) Adžić, R. R.; Wang, J. X. The Journal of Physical Chemistry B 1998, 102, 6305.

(25) Abd El Meguid, E. A.; Berenz, P.; Baltruschat, H. Journal of Electroanalytical Chemistry 1999, 467, 50.

(26) Saxena, S. D.; Gupta, K. S. Monatshefte für Chemie 1977, 108, 813.

(27) Clavilier, J.; Armand, D.; Sun, S. G.; Petit, M. Journal of Electroanalytical Chemistry and Interfacial Electrochemistry 1986, 205, 267. 
(28) Mostany, J.; Herrero, E.; Feliu, J. M.; Lipkowski, J. The Journal of Physical Chemistry B 2002, 106, 12787.

(29) Garcia-Araez, N.; Climent, V.; Rodriguez, P.; Feliu, J. M. Electrochimica Acta 2008, 53, 6793.

(30) Garcia-Araez, N. The Journal of Physical Chemistry C 2011, 115, 3075.

(31) Mostany, J.; Herrero, E.; Feliu, J. M.; Lipkowski, J. Journal of Electroanalytical Chemistry 2003, 558, 19.

(32) Garcia-Araez, N.; Climent, V.; Rodriguez, P.; Feliu, J. M. Langmuir 2010, $26,12408$.

(33) Herrero, E.; Feliu, J. M.; Aldaz, A. Journal of Electroanalytical Chemistry 1994, $368,101$.

(34) Buller, L. J.; Herrero, E.; Gómez, R.; Feliu, J. M.; Abruña, H. D. The Journal of Physical Chemistry B 2000, 104, 5932.

(35) Buller, L. J.; Herrero, E.; Gomez, R.; Feliu, J. M.; Abruna, H. D. Journal of the Chemical Society, Faraday Transactions 1996, 92, 3757.

(36) P.Rodriguez, N. G.-A., E.Herrero and J.M. Feliu In preparation. 